\title{
Impact of Smoking on Lifestyle and Vitality in College Students
}

\author{
Fumihiro Omasu' ${ }^{1}$, Azusa Komori², Kaeko Higashi' ${ }^{2}$, Haruka Yoshimura² \\ ${ }^{1}$ Department of Health and Nutrition, Faculty of Health and Nutrition, Yamagata Prefectural Yonezawa University of Nutrition \\ Sciences, Yamagata, Japan \\ ${ }^{2}$ Department of School Health, Faculty of Education, Kumamoto University, Kumamoto, Japan \\ Email: omasu@yone.ac.jp
}

How to cite this paper: Omasu, F., Komori, A., Higashi, K. and Yoshimura, H. (2021) Impact of Smoking on Lifestyle and Vitality in College Students. Open Journal of Preventive Medicine, 11, 199-210.

https://doi.org/10.4236/ojpm.2021.115016

Received: April 19, 2021

Accepted: May 25, 2021

Published: May 28, 2021

Copyright $\odot 2021$ by author(s) and Scientific Research Publishing Inc. This work is licensed under the Creative Commons Attribution International License (CC BY 4.0).

http://creativecommons.org/licenses/by/4.0/

\section{(c) (i) Open Access}

\begin{abstract}
There is a long history of studies on the bad influence of smoking on our bodies, with many study results accumulated to date indicating a decline in the smoking rate. However, the smoking rate in Japan is still higher than that in other countries. In order to reveal the various influences due to smoking, we examined the changes in lifestyle and vitality prior to and the following smoking, targeting college students who are at the early age of starting to smoke. The subjects were 213 college students ( 83 men and 130 women). Smoking frequency as well as sleeping, eating habits, exercise, and vitality as a lifestyle were surveyed through a questionnaire survey. As a result of comparing smoking and lifestyle between the smoking group and non-smoking group, in terms of sleep, the bedtime and wake-up time tended to be late in the smoking group. Regarding eating habits, there was a tendency for the smoking group to have a high rate of skipping breakfast and a high intake rate of midnight snacks. Regarding exercise, the number of people exercising on a daily basis was small in both the smoking group and the non-smoking group, with no significant difference observed. Therefore, this study revealed that smoking has a negative influence on some aspects of lifestyle. There was no significant relationship in terms of the effects of smoking on vitality. Going forward, it will be necessary to clarify the negative effects of smoking on mental health.
\end{abstract}

\section{Keywords}

Smoking, Lifestyle, Vitality, College Students

\section{Introduction}

One cause of lifestyle-related diseases is "smoking." Cigarettes contain many substances that are harmful to the body. Although the smoking rate of the Japanese 
has been declining from the peak, it is still high compared to other countries [1]. While the average smoking rate of adult Japanese women is $10 \%$, which is gradually decreasing from the peak, it remains at approximately the same level.

It is said that the generation with the highest ratio, in terms of the age to start smoking and the age that smoking becomes habitual, is in one's twenties. It is believed that if smoking has not started by this age, the chances of becoming a smoker thereafter are slim [2]. It is assumed that college students at the early age of smoking, in their twenties with the highest ratio, are likely to notice changes in lifestyle and vitality before and after smoking.

According to a previous study, with regard to the relationship between smoking and lifestyle, smokers generally acquire a more undesirable lifestyle, in terms of eating habits, stress, fatigue, drinking alcohol, bedtime, wake-up time, etc. [3]. It was found that the smoking rate increased as the frequency of habitual drinking of alcohol, skipping breakfast, and eating dinner out increased, in relation to basic lifestyle and smoking status, with those engaging in regular exercise having lower smoking rates than those without [3] [4].

According to a previous study, smoking behavior tends to increase the positive emotional effects of reducing "tension and excitement" and "anxiety" in habitual smokers [5]. On the other hand, there are negative effects such as a decrease in "exhilaration" and an increase in emotions of "fatigue" and "depression," with the existence of potential negative effects from smoking having also been reported among smokers. Therefore, in addition to the relationship between smoking and lifestyle, this study also focused on the relationship between smoking and vitality. The mental health degree [6], measured as a part of the factor analysis of the mental health item of the Varimax method, was expressed as vitality in this study.

The purpose of this study was to clarify the effect of smoking on lifestyle and vitality in college students at the age of starting to smoke.

\section{Methods}

The subjects were 213 Japanese college students ( 83 males and 130 females). All data in the present study were collected in 2018. It is thought that enough numerical objects and average college students are sorted out in this research [7]. The questionnaire survey was anonymous, with appropriate numbers for the answers marked with a circle [7].

Regarding the smoking status, we asked about their smoking rate, with each answer having four options: "smoke every day;" "smoke occasionally;" "used to smoke but quit;" and "have never smoked." These are described in the tables and sentences below as "every day," "occasionally," "quit," and "do not smoke." In Smoking-3, questions regarding the number of cigarettes smoked, four options were provided: " 31 or more;" " 21 to $30 ;$;" "11 to 20 ;" and " 10 or less."

Regarding lifestyle, items such as sleep, diet, and exercise were surveyed in the questionnaire. We asked regarding the average bedtime and wake-up time. Four options were provided for the question regarding the awakening status when 
waking up: "I awake feeling refreshed at my wake-up time;" "I awake at my wake-up time but do not feel refreshed;" "I wake up earlier than my wake-up time;" and "I cannot get up at my wake-up time." Four options were provided for the question regarding falling asleep: "I fall asleep fast and well;" "I can fall asleep if I close my eyes for a while;" "I am unable to fall asleep easily;" and "I wake up many times during the night." Four options were provided for the question regarding getting enough sleep: "I'm getting enough sleep;" "I'm getting more or less enough sleep;" "I'm not getting much sleep;" and "I'm not getting enough sleep."

Regarding the daily dietary intake status, the answers had three options: "I eat every day;" "I eat occasionally;" and "I rarely eat." Three options were provided for the question about snacking: "I eat often;" "I eat occasionally;" and "I rarely eat." Three options were provided for the question about midnight snacking: "I eat often;" "I eat occasionally;" and "I rarely eat." Four options were provided for the question about the frequency of drinking alcohol: "I drink alcohol almost every day;" "I drink alcohol 3 - 4 times a week;" "I drink alcohol 1 - 2 times a week;" and "I rarely drink alcohol."

Those who answered "Yes" to the question regarding whether or not they are currently engaging in any exercise or sports, were also asked to enter the name of the exercise or sport.

Part of the factor analysis [6] of the mental health item of the Varimax method was used, in order to measure the vitality of the subjects. There are 11 question items in total. The answers had four options: "not applicable;" "largely not applicable;" "somewhat applicable;" and "applicable." The question items 1 to 7 and 10 to 11 were given, for the measurement, 1 point for "not applicable," 2 points for "largely not applicable," 3 points for "somewhat applicable," and 4 points for "applicable." Question items 8 to 9 were given 4 points for "not applicable," 3 points for "largely not applicable," 2 points for "somewhat applicable," and 1 point for "applicable." All question items were summed up. Consequently, the total maximum score was 44 points, while the minimum score was 11 points.

The $\chi^{2}$ test was used to test the difference in frequency between the smoking group and the non-smoking group. All vitality scores were expressed as the mean \pm standard deviation. Analysis of variance was used for the difference in vitality scores between the smoking and non-smoking groups. Each level was set to less than $5 \%$.

\section{Results}

213 Japanese college students ( 83 males and 130 females) were targeted for analysis. The average age of subjects was $21.4 \pm 1.8$ years (mean \pm standard deviation).

\subsection{Smoking (Table 1)}

The results indicated 36 people (36.1\%) "smoke every day," 11 people (5.2\%) "smoke occasionally," 6 people (2.8\%) "used to smoke but quit," and 160 people 
Table 1. Smoking frequency by gender.

\begin{tabular}{cccccc}
\hline & Every day & Occasionally & Quit & Do not smoke & Total \\
\hline $\begin{array}{c}\text { Male (number } \\
\text { of males (\%)) }\end{array}$ & $30(36.1)$ & $8(9.6)$ & $3(3.6)$ & $42(50.6)$ & $83(39.0)$ \\
$\begin{array}{c}\text { Female (number } \\
\text { of females (\%)) }\end{array}$ & $6(4.6)$ & $3(2.3)$ & $3(2.2)$ & $118(90.8)$ & $130(61.0)$ \\
$\begin{array}{c}\text { Total (number } \\
\text { of people (\%)) }\end{array}$ & $36(16.9)$ & $11(5.2)$ & $6(2.8)$ & $160(75.1)$ & $213(100)$ \\
\hline
\end{tabular}

(75.1\%) "have never smoked." By gender, 30 (36.1\%) answered "smoke every day," 8 (9.6\%) answered "smoke occasionally," 3 (3.6\%) answered "used to smoke but quit," and 42 (50.6\%) answered "have never smoked" among males. Among females, 6 (4.6\%) answered "smoke every day," 3 (2.3\%) answered "smoke occasionally," 3 (2.2\%) answered "used to smoke but quit," and 118 (90.8\%) answered "have never smoked." Because most females were non-smokers, we decided to carry out the subsequent analysis on both males and females.

\subsection{Sleep}

The average bedtime indicated 2 people ( $0.9 \%)$ for " $21: 00$ to earlier than 23:00," 64 people (30.0\%) for "23:00 to earlier than 1:00," 121 people (56.8\%) for "1:00 to earlier than 3:00," 120 people (9.4\%) for "3:00 to earlier than 5:00," and 6 people $(2.8 \%)$ for "after 5:00." There was a significant difference in frequency among the smoking groups $(\mathrm{p}<0.01)$ (Table 2).

The average wake-up time indicated 3 people (1.4\%) for " $4: 00$ to earlier than $6: 00$," 63 people (30.0\%) for "6:00 to earlier than 8:00," 112 people $(53.3 \%)$ for "8:00 to earlier than 10:00," and 62 people (15.2\%) for "after 10:00." There was a significant difference in frequency among the smoking groups $(\mathrm{p}<0.01)$ (Table 3).

The survey indicated 54 people (25.4\%) for "I awake feeling refreshed at my wake-up time," 108 people (50.7\%) for "I awake at my wake-up time but do not feel refreshed," 9 people (4.2\%) for "I wake up earlier than my wake-up time," and 42 people (19.7\%) for "I cannot get up at my wake-up time." There was a significant difference in frequency among the smoking groups $(\mathrm{p}<0.05)$ (Table 4).

The survey indicated 87 people (40.8\%) for "I fall asleep fast and well," 91 people (42.7\%) for "I can fall asleep if I close my eyes for a while," 31 people (15.5\%) for "I cannot fall asleep easily," and 4 people (1.9\%) for "I wake up many times during the night" (Table 5). There was no significant difference by smoking frequency.

The survey indicated 70 people (33.6\%) for "I'm getting enough sleep," 108 people (50.9\%) for "I'm getting more or less enough sleep," 29 people (13.7\%) for "I'm not getting much sleep," and 5 people (2.4\%) for "I'm not getting 
Table 2. Average bedtime on weekdays by smoking frequency.

\begin{tabular}{ccccccc}
\hline & $21: 00-23: 00$ & $23: 00-1: 00$ & $1: 00-3: 00$ & $3: 00-5: 00$ & After 5:00 & Total \\
\hline $\begin{array}{c}\text { Every day } \\
\text { (number of people (\%)) }\end{array}$ & $0(0)$ & $2(5.6)$ & $21(58.3)$ & $10(27.8)$ & $3(8.3)$ & 36 \\
$\begin{array}{c}\text { Occasionally } \\
\text { (number of people (\%)) }\end{array}$ & $0(0)$ & $2(18.2)$ & $8(72.7)$ & $1(9.0)$ & $0(0)$ & 11 \\
$\begin{array}{c}\text { Quit (number } \\
\text { of people (\%)) }\end{array}$ & $1(16.7)$ & $1(16.7)$ & $2(33.3)$ & $2(33.3)$ & $0(0)$ & 6 \\
$\begin{array}{c}\text { Do not smoke } \\
\text { (number of people (\%)) }\end{array}$ & $1(16.7)$ & $59(36.9)$ & $90(56.2)$ & $7(4.4)$ & $3(1.9)$ & 160 \\
\hline
\end{tabular}
$\mathrm{p}<0.01$.

Table 3. Average wake-up time on weekdays by smoking frequency.

\begin{tabular}{cccccc}
\hline & $4: 00-6: 00$ & $6: 00-8: 00$ & $8: 00-10: 00$ & After 10:00 & Total \\
\hline $\begin{array}{c}\text { Every day } \\
\text { (number of people (\%)) }\end{array}$ & $0(0)$ & $2(5.6)$ & $19(52.8)$ & $15(41.7)$ & 36 \\
$\begin{array}{c}\text { Occasionally } \\
\text { (number of people (\%)) }\end{array}$ & $0(0)$ & $3(27.3)$ & $5(45.5)$ & $3(27.3)$ & 11 \\
$\begin{array}{c}\text { Quit (number } \\
\text { of people (\%)) }\end{array}$ & $0(0)$ & $1(16.7)$ & $3(50.0)$ & $2(33.3)$ & 6 \\
$\begin{array}{c}\text { Do not smoke } \\
\text { (number of people (\%)) }\end{array}$ & $3(1.9)$ & $57(36.3)$ & $85(54.1)$ & $12(21.1)$ & 157 \\
\hline
\end{tabular}
$\mathrm{p}<0.01$.

Table 4. "Do you awake refreshed in the morning?" by smoking frequency.

\begin{tabular}{cccccc}
\hline & $(1)$ & $(2)$ & $(3)$ & $(4)$ & Total \\
\hline $\begin{array}{c}\text { Every day (number of } \\
\text { people (\%)) }\end{array}$ & 6 & 19 & 0 & 11 & 36 \\
$\begin{array}{c}\text { Occasionally (number of } \\
\text { people (\%)) }\end{array}$ & 3 & $(52.8)$ & $(0)$ & $(30.6)$ & \\
Quit (number & $(27.3)$ & $(27.3)$ & $(18.2)$ & $(27.3)$ & 11 \\
of people (\%)) & 2 & 1 & 1 & 2 & 6 \\
$\begin{array}{c}\text { Do not smoke } \\
\text { (number of people (\%)) }\end{array}$ & $(33.3)$ & $(16.7)$ & $(16.7)$ & $(33.3)$ & \\
& 43 & 85 & 6 & 26 & 160
\end{tabular}

$\mathrm{p}<0.05$. (1) I awake feeling refreshed at my wake-up time; (2) I awake at my wake-up time but do not feel refreshed; (3) I wake up earlier than my wake-up time; and (4) I cannot get up at my wake-up time.

enough sleep" (Table 6). There was no significant difference by smoking frequency.

\subsection{Meals}

Regarding breakfast intake, the survey indicated 77 people (36.2\%) for "I eat every day," 53 people (24.9\%) for "I eat occasionally," and 83 people (39.0\%) for "I rarely eat". Regarding the intake of lunch, the survey indicated 180 people 
Table 5. "Fall asleep easily?" by smoking frequency.

\begin{tabular}{cccccc}
\hline & $(1)$ & $(2)$ & $(3)$ & $(4)$ & Total \\
\hline Every day (number of & 14 & 15 & 6 & 1 & 36 \\
people (\%)) & $(38.9)$ & $(41.7)$ & $(16.7)$ & $(2.8)$ & \\
Occasionally (number of & 6 & 2 & 3 & 0 & 11 \\
people (\%)) & $(54.5)$ & $(18.1)$ & $(27.3)$ & $(0)$ & \\
Quit (number of & 1 & 3 & 2 & 0 & 6 \\
people (\%)) & $(16.7)$ & $(50.0)$ & $(33.3)$ & $(0)$ & \\
Do not smoke (number & 66 & 71 & 20 & 3 & 160 \\
of people (\%)) & $(41.3)$ & $(44.4)$ & $(12.5)$ & $(1.9)$ & \\
\hline
\end{tabular}

N.S. (1) I fall asleep fast and well; (2) I can fall asleep if I close my eyes for a while; (3) I cannot fall asleep easily; and (4) I wake up many times during the night.

Table 6. "Do you feel that you are getting enough sleep?" by smoking frequency.

\begin{tabular}{cccccc}
\hline & $(1)$ & $(2)$ & $(3)$ & $(4)$ & Total \\
\hline Every day (number of & 14 & 14 & 6 & 2 & 36 \\
people (\%)) & $(38.9)$ & $(38.9)$ & $(16.7)$ & $(5.6)$ & \\
& & & & & \\
Occasionally (number & 4 & 4 & 2 & 0 & 10 \\
of people (\%)) & $(40.0)$ & $(40.0)$ & $(20.0)$ & $(0)$ & \\
Quit (number of people (\%)) & 3 & 2 & 0 & 0 & 5 \\
Do not smoke (number & $(60.0)$ & $(40.0)$ & $(0)$ & $(0)$ & \\
of people (\%)) & 49 & 88 & 21 & 3 & 161 \\
\hline
\end{tabular}

N.S. (1) I'm getting enough sleep; (2) I'm getting more or less enough sleep; (3) I'm not getting much sleep; and (4) I'm not getting enough sleep.

(36.7\%) for "I eat every day," 31 people (9.9\%) for "I eat occasionally," and 2 people $(0.9 \%)$ for "I rarely eat." Regarding the intake of dinner, the results indicated 178 people (83.6\%) for "I eat every day," 32 people (15.5\%) for "I eat occasionally," and 4 people (1.9\%) for "I rarely eat." There was a significant difference in frequency among the smoking groups $(\mathrm{p}<0.01)$ (Table 7).

The survey indicated 75 people (35.2\%) for "I eat often," 112 people (52.6\%) for "I eat occasionally," and 26 people (12.2\%) for "I rarely eat." There was a significant difference in frequency among the smoking groups $(\mathrm{p}<0.01)$ (Table 8).

The survey indicated 30 people (14.1\%) for "I eat often," 72 people (33.8\%) for "I eat occasionally," and 111 people (52.1\%) for "I rarely eat." There was a significant difference in frequency among the smoking groups $(\mathrm{p}<0.05)$ (Table 9).

The results indicated 60 people (28.2\%) for "I by and large do not care," 143 people (67.1\%) for "I care a little," and 10 people (4.7\%) for "I care a lot." There was a significant difference in frequency among the smoking groups $(\mathrm{p}<0.01)$ (Table 10).

The survey indicated 7 people (3.3\%) for "I drink alcohol almost every day," 17 people (8.0\%) for "I drink alcohol 3 - 4 times a week," 77 people $(36.2 \%)$ for "I drink alcohol 1 - 2 times a week," and 112 (52.6\%) for "I rarely drink alcohol." 
Table 7. Intake status by smoking frequency.

\begin{tabular}{|c|c|c|c|c|c|c|c|c|c|c|}
\hline & \multicolumn{3}{|c|}{ Breakfast } & \multicolumn{3}{|c|}{ Lunch } & \multicolumn{3}{|c|}{ Dinner } & \multirow{2}{*}{ Total } \\
\hline & (0) & $\circ$ & $x$ & (2) & $\circ$ & $x$ & (2) & $\circ$ & $x$ & \\
\hline $\begin{array}{c}\text { Every day } \\
\text { (number of } \\
\text { people (\%)) }\end{array}$ & $\begin{array}{c}3 \\
(8.3)\end{array}$ & $\begin{array}{c}10 \\
(27.8)\end{array}$ & $\begin{array}{c}23 \\
(63.9)\end{array}$ & $\begin{array}{c}24 \\
(66.7)\end{array}$ & $\begin{array}{c}10 \\
(27.8)\end{array}$ & $\begin{array}{c}2 \\
(5.6)\end{array}$ & $\begin{array}{c}26 \\
(72.2)\end{array}$ & $\begin{array}{c}8 \\
(22.2)\end{array}$ & $\begin{array}{c}2 \\
(5.6)\end{array}$ & 36 \\
\hline $\begin{array}{l}\text { Occasionally } \\
\text { (number of } \\
\text { people }(\%) \text { ) }\end{array}$ & $\begin{array}{c}1 \\
(9.0)\end{array}$ & $\begin{array}{c}5 \\
(45.5)\end{array}$ & $\begin{array}{c}5 \\
(45.5)\end{array}$ & $\begin{array}{c}8 \\
(72.7)\end{array}$ & $\begin{array}{c}3 \\
(27.3)\end{array}$ & $\begin{array}{c}0 \\
(0)\end{array}$ & $\begin{array}{c}9 \\
(81.8)\end{array}$ & $\begin{array}{c}2 \\
(18.2)\end{array}$ & $\begin{array}{c}0 \\
(0)\end{array}$ & 11 \\
\hline $\begin{array}{c}\text { Quit } \\
\text { (number of } \\
\text { people }(\%) \text { ) }\end{array}$ & $\begin{array}{c}3 \\
(50.0)\end{array}$ & $\begin{array}{c}1 \\
(16.7)\end{array}$ & $\begin{array}{c}2 \\
(33.3)\end{array}$ & $\begin{array}{c}4 \\
(66.7)\end{array}$ & $\begin{array}{c}2 \\
(33.3)\end{array}$ & $\begin{array}{c}0 \\
(0)\end{array}$ & $\begin{array}{c}4 \\
(66.7)\end{array}$ & $\begin{array}{c}1 \\
(33.3)\end{array}$ & $\begin{array}{c}0 \\
(0)\end{array}$ & 6 \\
\hline $\begin{array}{c}\text { Do not smoke } \\
\text { (number of } \\
\text { people }(\%) \text { ) }\end{array}$ & $\begin{array}{c}70 \\
(43.8)\end{array}$ & $\begin{array}{c}37 \\
(23.1)\end{array}$ & $\begin{array}{c}53 \\
(33.1)\end{array}$ & $\begin{array}{c}144 \\
(90.0)\end{array}$ & $\begin{array}{c}16 \\
(10.0)\end{array}$ & $\begin{array}{c}0 \\
(0)\end{array}$ & $\begin{array}{c}139 \\
(86.9)\end{array}$ & $\begin{array}{c}21 \\
(13.1)\end{array}$ & $\begin{array}{c}2 \\
(1.3)\end{array}$ & 160 \\
\hline
\end{tabular}

$\mathrm{p}<0.01$, O: I eat every day; $\bigcirc$ : I eat occasionally; $\times$ : I rarely eat.

Table 8. "Do you eat snacks?" by smoking frequency.

\begin{tabular}{ccccc}
\hline & I eat often & I eat occasionally & I rarely eat & Total \\
\hline $\begin{array}{c}\text { Every day (number of } \\
\text { people (\%)) }\end{array}$ & $11(30.6)$ & $14(38.9)$ & $11(30.6)$ & 36 \\
$\begin{array}{c}\text { Occasionally (number of } \\
\text { people (\%)) }\end{array}$ & $3(27.3)$ & $6(54.4)$ & $2(18.2)$ & 11 \\
$\begin{array}{c}\text { Quit (number of people } \\
(\%))\end{array}$ & $1(16.7)$ & $3(50.0)$ & $2(33.3)$ & 6 \\
$\begin{array}{c}\text { Do not smoke (number } \\
\text { of people (\%)) }\end{array}$ & $60(37.5)$ & $89(55.6)$ & $11(6.9)$ & 160 \\
\hline $\mathrm{p}<0.01$. & & &
\end{tabular}

Table 9. "Do you eat a midnight snack?” by smoking frequency.

\begin{tabular}{ccccc}
\hline & I eat often & I eat occasionally & I rarely eat & Total \\
\hline $\begin{array}{c}\text { Every day (number of } \\
\text { people (\%)) }\end{array}$ & $10(27.8)$ & $17(47.2)$ & $9(25.0)$ & 36 \\
$\begin{array}{c}\text { Occasionally (number of } \\
\text { people (\%)) } \\
\text { Quit (number of people } \\
(\%))\end{array}$ & $2(18.2)$ & $4(36.4)$ & $5(45.5)$ & 11 \\
$\begin{array}{c}\text { Do not smoke (number } \\
\text { of people (\%)) }\end{array}$ & $0(0)$ & $2(33.3)$ & $4(66.7)$ & 6 \\
\hline $\mathrm{p}<0.05$. & $49(30.6)$ & $93(58.1)$ & 160 \\
\end{tabular}

There was a significant difference in frequency among the smoking groups ( $\mathrm{p}<$ 0.01) (Table 11).

\subsection{Exercise}

The survey indicated 72 people (35.6\%) for "I am currently engaging in some 
Table 10. "Do you care about the nutritional balance of each meal?" by smoking frequency.

\begin{tabular}{ccccc}
\hline & $(1)$ & $(2)$ & $(3)$ & Total \\
\hline $\begin{array}{c}\text { Every day (number of } \\
\text { people (\%)) }\end{array}$ & $23(63.9)$ & $11(30.6)$ & $2(5.6)$ & 36 \\
$\begin{array}{c}\text { Occasionally (number } \\
\text { of people (\%)) }\end{array}$ & $7(63.6)$ & $4(36.4)$ & $0(0)$ & 11 \\
$\begin{array}{c}\text { Quit (number } \\
\text { of people (\%)) }\end{array}$ & $1(16.7)$ & $4(66.7)$ & $1(16.7)$ & 6 \\
$\begin{array}{c}\text { Do not smoke } \\
(\text { number of people (\%)) }\end{array}$ & $29(18.1)$ & $124(77.5)$ & $7(4.4)$ & 160 \\
\hline
\end{tabular}

$\mathrm{p}<0.01$. (1) I by and large do not care; (2) I care a little; and (3) I care a lot.

Table 11. "How often do you drink alcohol?" by smoking frequency.

\begin{tabular}{cccccc}
\hline & $(1)$ & $(2)$ & $(3)$ & $(4)$ & Total \\
\hline $\begin{array}{c}\text { Every day (number of } \\
\text { people (\%)) }\end{array}$ & $4(11.1)$ & $8(22.2)$ & $16(44.4)$ & $8(22.2)$ & 36 \\
$\begin{array}{c}\text { Occasionally (number } \\
\text { of people (\%)) }\end{array}$ & $0(0)$ & $3(27.3)$ & $6(54.5)$ & $2(18.2)$ & 11 \\
$\begin{array}{c}\text { Quit (number of people } \\
(\%))\end{array}$ & $0(0)$ & $0(0)$ & $5(83.3)$ & $1(16.7)$ & 6 \\
$\begin{array}{c}\text { Do not smoke (number } \\
\text { of people (\%)) }\end{array}$ & $3(1.9)$ & $6(3.8)$ & $50(31.3)$ & $101(63.1)$ & 160 \\
\hline
\end{tabular}

$\mathrm{p}<0.01$, (1) I drink alcohol almost every day; (2) I drink alcohol 3 - 4 times a week; (3) I drink alcohol 1 - 2 times a week; and (4) I rarely drink alcohol.

exercise or sports," 130 people (64.4\%) for "I am currently not engaging in any exercise or sports" (Table 12). There was no significant difference by smoking frequency. Among those who answered, "I am currently engaging in some exercise or sports," the content of exercise and sports specifically included baseball, soccer, volleyball, badminton, tennis, basketball, and Shorinji Kempo.

\subsection{Vitality}

The overall average score and standard deviation was $31.4 \pm 5.6$. The overall male score and standard deviation was $31.6 \pm 5.6$, while the female average score and standard deviation was $31.4 \pm 5.6$ (Table 13 ). There was no significant difference in scores between males and females.

The average score and standard deviation by smoking frequency indicated $31.2 \pm 7.2$ for "I smoke every day," $31.1 \pm 5.5$ for "I smoke occasionally," $33.7 \pm$ 6.6 for "I used to smoke but quit," and $31.4 \pm 5.2$ for "I have never smoked" (Table 14). Although the score tended to be higher in the "quit" group, there was no significant difference in vitality score by smoking frequency. 
Table 12. "Are you currently engaging in any exercise or sports?" by smoking frequency.

\begin{tabular}{cccc}
\hline & Yes & No & Total \\
\hline Every day (number of people (\%)) & $13(38.2)$ & $21(61.8)$ & 34 \\
Occasionally (number of people (\%)) & $7(63.6)$ & $4(36.4)$ & 11 \\
Quit (number of people (\%)) & $1(20.0)$ & $4(80.0)$ & 5 \\
Do not smoke (number of people (\%)) & $51(33.6)$ & $101(66.4)$ & 152 \\
\hline
\end{tabular}

N.S.

Table 13. Average score \pm standard deviation.

\begin{tabular}{cc}
\hline & Average score \pm standard deviation \\
\hline Overall & $31.4 \pm 5.6$ \\
Males & $31.6 \pm 5.6$ \\
Females & $31.4 \pm 5.6$ \\
\hline
\end{tabular}

N.S.

Table 14. Average score \pm standard deviation by smoking frequency.

\begin{tabular}{cc}
\hline & Average score \pm standard deviation \\
\hline Every day & $31.2 \pm 7.2$ \\
Occasionally & $31.1 \pm 5.5$ \\
Quit & $33.7 \pm 6.6$ \\
Do not smoke & $31.4 \pm 5.2$ \\
\hline
\end{tabular}

N.S.

\section{Discussion}

Those with smoking frequencies of "smoke every day" and "smoke occasionally" are classified as being in the "smoking group," while those of "used to smoke but quit" and "have never smoked" are classified as being in the "non-smoking group." Regarding bedtime, it was found that the percentage of individuals going to bed from 1:00 to earlier than 3:00 was commonly highest in the smoking group and non-smoking group, while it was also found that the percentage of individuals going to bed from 23:00 to earlier than 1:00 was high in the group of "have never smoked" in the non-smoking group. Among those in the smoking group, the percentage of individuals going to bed after 5:00 was $13.9 \%$ in the group of "smoke every day," which was higher than the other groups. Moreover, regarding wake-up time, it was found that the percentage of individuals waking up from 8:00 to earlier than 10:00 was commonly highest in the smoking group and non-smoking group, while it was also found that the percentage of individuals waking up after 10:00 was high in the group of "smoke every day" in the smoking group. Accordingly, it is believed that the bedtime and wake-up time of those in the smoking group are later than those in the non-smoking group. In terms of smoking status and lifestyle, it has been reported that there was a significant difference between the smoking status and bedtime, wake-up time, and 
average sleep time, with a high rate of acquiring an undesirable lifestyle among those in the smoking group [3].

Regarding breakfast intake, it was found that while half of the non-smoking group eat breakfast every day, the intake rate drops below $10 \%$ in the smoking group, with over $60 \%$ of them rarely eating. In previous studies [8] [9] [10], it was stated that many individuals who skip breakfast are smokers, both men and women. As stated above, since there is a tendency for those in the smoking group to have a later bedtime as well as wake-up time, it is believed that this is related to having no time for breakfast. Regarding the intake of lunch, the rate of individuals having lunch every day was high in both groups. Especially among those in the non-smoking group, the rate of individuals having lunch every day in the "have never smoked" group was over $90 \%$.

The intake rate of snacks turned out to be higher among those in the nonsmoking group than the smoking group. There is a report [11] indicating that the rate of snacking is higher in non-smokers than habitual smokers. It is believed that this loss of appetite due to changes in the sense of taste from smoking is a contributing factor as to why those in the smoking group are less prone to eating snacks than those in the non-smoking group. There is a report [12] indicating that as one popular lifestyle obstacle related to the oral cavity, smokers "cannot appreciate meals." The intake rate of midnight snacks was higher among those in the smoking group than those in the non-smoking group. As stated above, it is believed that this is related to bedtime. It is believed that since those in the smoking group go to bed later than those in the non-smoking group, the intake rate of midnight snacks between dinner and bedtime is high.

In regard to exercise, the number of individuals who answered, "I am currently engaging in some form of exercise or sports," was lower than those who are not exercising in both the smoking and non-smoking groups. However, no significant difference was confirmed. The fact that there are generally few opportunities for college students to regularly exercise like in a sports club is believed to be affecting these results. Furthermore, there was an opinion among smokers indicating that the reason why they are not exercising is "because exercise is tough." This is believed to be related to a decline in lung capacity due to smoking [13] [14].

There was no significant relationship between smoking and vitality in this study. It has been reported [5] that smoking has negative effects such as a decrease in refreshing feelings, fatigue, and worsening of depression. On the other hand, it is also stated that smoking tends to increase the positive emotional effects of reducing tension, excitement, and anxiety. There is also a previous study [15] reporting that the self-esteem and self-efficacy of non-smoking students are higher than those of smoking students. However, we were unable to confirm a relation to smoking with the index of vitality used in this study.

There are several limitations in this study. The number of the smoking subjects was small and the study had a cross-sectional design. Also, the question- 
naire used in this study is a simple questionnaire based on self-report about lifestyle and vitality. While this study conducted a survey targeting college students, a low number of smokers among the subjects is also believed to be one of the reasons why no significant relationship between smoking and vitality was observed. Future improvements include conducting a survey among individuals of all ages rather than limiting the subjects to college students, increasing the number of questions in the questionnaire, etc.

\section{Conclusion}

As a result of comparing smoking and lifestyle between the smoking group and the non-smoking group, regarding sleep, there was a tendency for the bedtime and wake-up time in the smoking group to be late. Regarding meals, there was a tendency for the smoking group to have a high rate of skipping breakfast and a high intake rate of midnight snacks. Regarding exercise, the number of people exercising on a daily basis was small in both the smoking group and the non-smoking group, with no significant difference observed. Therefore, it was suggested that smoking has a negative effect on some aspects of lifestyle. There was no significant relationship in terms of the effects of smoking on vitality. Going forward, it will be necessary to clarify the possibility that smoking has a negative effect on mental health.

\section{Conflicts of Interest}

The authors declare no conflicts of interest regarding the publication of this paper.

\section{References}

[1] Usuda, K., Konno, K., Kono, K. and Tamashiro, H. (2002) WHO's Framework Convention on Tobacco Control Potential Impact on Tobacco Control in Japan. Japanese Journal of Public Health, 49, 236-245. (In Japanese)

[2] The International Bank for Reconstruction and Development/The World Bank (1999) Curbing the Epidemic: Government and the Economics of Tobacco Control. 1818 H Street, N.W., Washington, D.C. 20433, U.S.A.

[3] Kurioka, N., Kitada, M., Yoshii, C., Inagaki, K., Sezai, I. and Kano, M. (2009) The Relationship between Female Students' Perception towards Tobacco Smoking and Their Lifestyle as Analyzed Using the Kano Test for Social Nicotine Dependence (KTSND). Japanese Journal of Tobacco Control, 4, 33-44. (In Japanese)

[4] Ferrucci, L., Izmirlian, G., Leveille, S., Phillips, C.L., Corti, M.C., Brock, D.B. and Guralnik, J.M. (1999) Smoking, Physical Activity, and Active Life Expectancy. American Journal of Epidemiology, 149, 645-653. https://doi.org/10.1093/oxfordjournals.aje.a009865

[5] Ohashi, K., Tabata, R., Hayashi, S., Hata, T. and Arakawa, C. (2005) The Evaluations of the Psychological Effects of Smoking and the Parasympathetic Nerve Activity Induced by Smoking. Journal of Nursing, Shiga University of Medical Science, 3, 33-41. (In Japanese)

[6] Tokunaga, M., Okabe, H., Kanezaki, R. and Tatano, H. (1984) A Study on the Di- 
agnostic Indexes for Health and It's Related Factors. Journal of Health Science, 6, 155-164. (In Japanese)

[7] Omasu, F., Uemura, S. and Yukizane, S. (2015) The Impact of Family Relationships on the Smoking Habits of University Students. Open Journal of Preventive Medicine, 5, 14-22. https://doi.org/10.4236/ojpm.2015.51002

[8] Keski-Rahkonen, A., Kaprio, J., Rissanen, A., Virkkunen, M. and Rose, R.J. (2003) Breakfast Skipping and Health-Compromising Behaviors in Adolescents and Adults. European Journal of Clinical Nutrition, 57, 842-53. https://doi.org/10.1038/sj.ejcn.1601618

[9] Pendergast, F.J., Livingstone, K.M., Worsley, A. and McNaughton, S.A. (2019) Examining the Correlates of Meal Skipping in Australian Young Adults. Nutrition Journal, 18, Article No. 24. https://doi.org/10.1186/s12937-019-0451-5

[10] Sakata, K., Matumura, Y., Yoshimura, N., Tamaki, J., Hashimoto, T., Oguri, S., Okayama, A. and Yanagawa, H. (2001) Relationship between Skipping Breakfast and Cardiovascular Disease Risk Factors in the National Nutrition Survey Data. Japanese Journal of Public Health, 48, 837-841. (In Japanese)

[11] Nishiyama, M., Yasugi, H. and Ohishi, K. (2009) Lifestyle and Attitudes towards Smoking among Smokers and Non-Smokers in a Japanese University: Repeatedly Measured cross Sectional Study of Paramedical Students. Japanese Journal of Health and Human Ecology, 75, 18-29. (In Japanese) https://doi.org/10.3861/jshhe.75.18

[12] Furukawa, S., Mori, C., Ueno, M., Shinada, K. and Kawaguchi, Y. (2008) Association of Smoking Status with Oral-Health-Related Daily Life Difficulties among Japanese Male Workers. Journal of Dental Health, 58, 33-43.

[13] Tzani, P., Aiello, M., Colella, M., Verduri, A., Marangio, E., Olivieri, D. and Chetta, A. (2008) Lung Diffusion Capacity Can Predict Maximal Exercise in Apparently Healthy Heavy Smokers. Journal of Sports Science and Medicine, 7, 229-234.

[14] Kelder, S.H., Perry, C.L., Klepp, K.I. and Lytle, L.L. (1994) Longitudinal Tracking of Adolescent Smoking, Physical Activity, and Food Choice Behaviors. American Journal of Public Health, 84, 1121-1126. https://doi.org/10.2105/AJPH.84.7.1121

[15] Hale, W.J., Perrotte, J.K., Baumann, M.R. and Garza, R.T. (2015) Low Self-Esteem and Positive Beliefs about Smoking: A Destructive Combination for Male College Students. Addictive Behaviors, 46, 94-99. https://doi.org/10.1016/j.addbeh.2015.03.007 